\title{
Headache Clinic in a Psychiatric Hospital
}

Neha Sayeed*, Jyoti Mishra, Sayeed Akhtar, C.R.J. Khess, Avinash Sharma

\begin{abstract}
INTRODUCTION:
Headache as a symptom can be primary or secondary. As regards primary headache the psychological facors can serve as the sole basis of headache (e.g. conversion, hypochondriasis, somatization and somatoform pain disorders)'.Merskey (1965)' and Large (1980) have reported a high incidence of neurosis and depression with an incidence rate of more than $50 \%$ in some studies ${ }^{5}$. Many patients with purely psychiartic morbidity may find the headache clinic a more attractive and less stigmatizing option to roll themselves for Psychiatric treatment, Hence the study was planned. The aim of the study was to fine out the frequency of patients with primary headache syndromes, co-morbid psychiatric diagnoses or psychiatric morbidity in patients enrolling themselves in the headache clinic located in a psychiatric hospital. The implication of the study has been discussed.
\end{abstract}

Keyword: Primary Headache

\section{MATERIALAND METHODS:}

The study was conducted at the Central Institute of Psychiatry, which is a 643-bed postgraduate teaching institute. The institute runs various special clinics such as the epilepsy clinic and the skin and venereal disease clinic. The headache clinic was established in August 1995 as an outpatient treatment facility. The clinic is held once a week. Patients who are registered at the headache clinic are examined by junior residents who record the history and physical findings in a case record file designed for the clinic. The findings are then discussed with the consultant andthe final diagnosis is made. In case of any suspicion of organic etiology of headache, the patients are subjected to EEG and CT scan available in the facility itself. Whenever there is a possible psychiatric disorder present, a thorough mental status examination and diagnostic psychometry is undertaken. The classification and diagnostic criteria for headache disorders, cranial neuralgias, and facial pain are used for the diagnoses of headache. For patients with a psychiatric disorder, the International Classification of Diseases (ICD)-10[7] criteria is used. For this study, the case records of all patients attending the headache clinic during a 12-month period (from January 2008 to December 2008) were reviewed. The socio-demographic and clinical details, along with the diagnoses, were recorded on a specially designed form. The diagnoses were independently reviewed by at least two researchers and, only when there was a consensus, a final diagnosis was assigned. For patients with evidence of psychiatric problems, either from the history, mental status examination, or diagnostic psychometry, it was ensured that they fulfilled the ICD10 criteria for a definite psychiatric disorder before being assigned a psychiatric diagnosis.

\section{RESULTS:}

Two hundred and twenty patients were included in the study, of whom 97 (44\%) were male and $123(56 \%)$ were female. The mean age of the patients was $31.25 \pm 10.57$ years. The mean age of the males and females did not differ significantly (30.79 \pm 10.80 years compared with $31.5 \pm 10.46$ years). The diagnoses of the study population by gender are shown in

\section{Table 1.}

Sixty two (28\%) had a primary diagnosis of a psychiatric disorder. Depression was the commonest psychiatric disorder and was seen in 39 patients with headache $(22.20 \%)$. This was followed by generalized anxiety disorder (GAD) in 10 patients with headache (4.5\%) and somatization disorder in five $(2.2 \%)$. Three patients $(1.36 \%)$ had obsessive compulsive disorder (OCD), and an equal number had hypochondriasis $(1.36 \%)$ and two $(1.36 \%)$ had schizophrenia. 
Table 1. Diagnoses of the study population according to gender.

$\begin{array}{llll}\text { DIAGNOSIS } & \text { MALE } & \text { FEMALE } & \text { TOTAL } \\ \text { Migraine } & 22 & 42 & 64 \\ \text { Tension Headache } & 17 & 29 & 46 \\ \text { Mixed Headache } & 12 & 18 & 30 \\ \text { Depression } & 22 & 17 & 39 \\ \text { Anxiety } & 06 & 4 & 10 \\ \text { Somatization } & 01 & 4 & 05 \\ \text { Hypochondriasis } & 2 & 1 & 03 \\ \text { Conversion reaction } & 1 & 2 & 3 \\ \text { Schizophrenia } & 2 & - & 2 \\ \text { Trigeminal Neuralgia } & 2 & -2 & \\ \text { Sinusitis } & 2 & - & 1 \\ \text { Refractive error } & 4 & 3 & 7 \\ \text { Others } & 04 & 31 & 07 \\ \text { Total } & 97 & 123 & 220\end{array}$

\section{DISCUSSION:}

In this study, there was a preponderance of female patients, which was contrary to expectation since earlier outpatient based studies done at this institute and at other centres in India have consistently found an over-representation of male patients. ${ }^{\text {ss.on }}$ The commonest disorder among the study population was migraine $(29 \%)$, followed by tension headache $(20.90 \%)$ and mixed headache syndrome $(13.6 \%)$. These disorders are known to be more prevalent among females. ${ }^{\text {m.n.mal }}$ In our sample, $70 \%$ of the patients suffering from migraine, tension headache and mixed headache were female, which was consistent with the views of Adler and Adler"' that women are nearly threefold more likely to have this disorder than men. Hence, this could explain the over-representation of females in the study population. A large body of evidence indicates that women are more prone to unipolar depression, which is supported from two sources of data on the rates of depression in men and women - records of persons treated for depression and surveys of the general population. ${ }^{n-1}$ However, in our study we found an overrepresentation of males. The preponderance of males in the study cannot be explained by increased frequency of depression. A possible explanation could be the difference in the active response style of men towards their depressed mood as compared with women. Chevron et al. ${ }^{\text {"si }}$ are of the opinion that men and women experience depressive symptoms equally frequently and to the same degree, but because depression is perceived to be 'feminine', men are less likely to admit to it. Hence, a seriously depressed man might be unwilling to admit to depression and seek help for depressive symptoms. ${ }^{\text {nd }}$ However, headache may be more consistent with the male sex-role stereotype and perhaps more acceptable.

The number of patients with primary psychiatric diagnosis attending a headache clinic located in a psychiatric set-up is an interesting finding. Patients with depressive symptoms, generalized anxiety disorder, somatization disorders, hypochondriasis, conversion disorder and even patients with schizophrenia had enrolled themselves in the headache clinic. Moreover, the number of patients with tension headache having mixed headache may require detailed psychological evaluation and those who have mixed headache syndrome. All such cases had reported headache as a symptom but during history taking and mental status examination, the real diagnosis was delineated. It may be possible that patients of schizophrenia might have been coaxed into enrolling in the headache clinic to make them comfortable that they have been being consulted for headache and not for being "crazy". In our opinion, the headache clinic may be an attractive tool in a psychiatric OPD to bring about a change in the image of a mental hospital and it may make the services more attractive, acceptable and less stigmatizing for patients who have no overt psychotic symptoms and who don't consider themselves having any sign of "madness" as they call it.

\section{References:}

1. Rose C.F. \& Lipton,R.B.Headache Clinics in The Headache,Ed. Olesn ,J ,Tfelt-Hansen ,P \& Welch K.M.A.,New York, Raven Press, 1993 :p. 865-869

2. Andrasik F. Psychological and behavioral aspects of chronic headache. Neurol Clin 1990;8:961-76.

3. Merskey H. The characteristics of persistent pain in psychological illness. J Psychosom Res 1965;9:291-98.

4. Large RG. The psychiatrist and the chronic pain patient: 172 anecdotes. Pain 1980;9:253-63.

5. Kudrow L. Tension headache (scalp muscle contraction headache). In: Appenzeller O, ed. Pathogenesis and treatment of headache. New York: Spectrum; 1976.

6. Diamond S. Depression and headache. Headache 1983;23:122-26. 
7. The ICD-10 classification of mental and behavioral disorders. Clinical description and diagnostic guidelines. Geneva: World Health Organization; 1992.

8. Khanna R, Gupta N, Shankar S. Course of bipolar disorders in Eastern India. JAffect Disord 1992;24:35-41.

9. Khess CRJ, Akhtar S, Jagawat $\mathrm{T}$, et al. Gender and psychopathology in obsessive compulsive disorder. Indian J Psychiatry 1996;38:166-71.

10. Khess CRJ, Das J, Akhtar S. Four year follow up of first episode manic patients. Indian J Psychiatry 1997;39:160-65.

11. Adler CS, Adler SM. The migraine patient: descriptive studies. In: Adler CS, Adler SM, Packard RC, eds. Psychiatric aspects of headache. Baltimore: Williams and Wilkins; 1987:131-41.

12. Weissman MM, Klerman GL. Sex differences in the epidemiology of depression. Arch Gen Psych 1977;34:98-111.

13. Boyd JH, Weissman MM. Epidemiology of affective disorders: a re-examination and future directions. Arch Gen Psych 1981;38:1039-46.
14. Nolen Hoeksema S. Sex difference in unipolar depression: evidence and theory. Psycho Bull 1987;101:259-82.

15. Chevron ES, Quinlan DM, Blatt SJ. Sex roles and gender differences in the expression of depression. J Abnor Psychol 1978;87:680-83.

16. Phillips DL, Segal BE. Sexual status and psychiatric symptoms. Am Sociol Rev 1969;34:58-72.

17. Hirschfeld RMA, Cross CK. Epidemiology of affective disorders: psychosocial risk factors. Arch Gen Psych 1982;39:35-46.

1- M. Phil(M\&SP) Student, CIP, Kanke

2- M. Phil(M\&SP) Student, CIP, Kanke

3- Deputy Medical Superintendant, CIP, Kanke

4- Professor of Psychiatry, CIP, Kanke

5- Junior Resident, Central Institute of Psychiatry Ranchi - 834006, Jharkhand State 